\title{
Division of Epidemiology and Clinical Applications
}

National Cancer Institute

\section{Source}

National Cancer Institute. Division of Epidemiology and Clinical Applications. NCI

Thesaurus. Code C82615.

A division of the National Eye Institute that has the mission to plan, develop, and conduct human population studies concerned with the cause, prevention, and treatment of eye disease and vision disorders, with emphasis on the major causes of blindness and visual impairment. They also carry out programs of education in biometric and epidemiologic principles and methods for the vision research community as well as providing biometric and epidemiologic assistance to National Eye Institute intramural and extramural staff and to vision research workers elsewhere. 